promulgate his aims. Now Britain's foremost childbirth charity, The National Childbirth Trust, offers information and support in pregnancy, childbirth, and early parenthood. It aims to enable every parent to make informed choices. The first president of the Trust, $\mathrm{Dr}$ Grantly Dick-Read, would have welcomed the way his work has become today's good practice, even if recognition of his contribution is belated.

VALERIE ALLEN Alexandra House, Oldham Terrace, Acton, London W3 $6 \mathrm{NH}$

1 Dunn PM. Dr Grantly Dick-Read (1890-1959) of Norfolk and natural childbirth. Arch Dis Child 1994; 71: F145-6.

\section{Formula mistake}

EDITOR,-We would like to point out an error which appeared in our article published in the May issue of your journal. The formula for gallbladder volume was erroneous. The correct formula is:

Gallbaldder volume $\left(\mathrm{mm}^{3}\right)=$

$\Pi \times$ maximum length $(\mathrm{mm}) \times$ maximum width $(\mathrm{mm}) \times$ maximum height $(\mathrm{mm})$ A PIERRO
Institute of Child Health and Great Ormond Street Hospital for Children NHS Trust, University of London 30 Guilford Street,

1 Jawaheer G, Pierro A, Lloyd D A, Shaw N J. Gall bladder contractility in neonates: effects of parenteral and enteral feeding. Arch Dis Child 1995; 72: F200-2.

\section{BOOK REVIEWS}

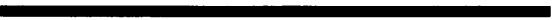

Neurology of the newborn. 3rd Edn. Joseph J Volpe (pp 876, $£ 65$ hardback) WB Saunders Co, 1995; ISBN 0-7216-3690-X.

To paraphrase the fashion journalists, this is the season's 'must-have'. Sixty five pounds barely covers a subscription to one of the glossy magazines but, amazingly, it does buy the fruits of Professor Volpe's hard labour over the past seven years. To produce a high quality, readable, comprehensive synthesis of this vast pool of knowledge would be a major achievement for a dedicated group of authors. Volpe has accomplished the feat single handed. How has he done it? Open mouthed in admiration I envisaged whole teams gathering reference material from the Harvard medical school library, armies of secretaries typing on word processors fitted with lightning-fast pentium chips, graphic artists drawing by night...but the ackowledgements refer only to his secretary and his wife.

Each chapter reads like the expert review that it is, and the single authorship avoids repetition and ensures a rare uniformity of style. Particularly good were the chapters reviewing the experimental work on plasticity and myelination of the CNS, and those on hypoxic-ischaemic encephalopathy. But there is something on every aspect of neonatal neurology from the management of rare and complex disorders of gyration, through periventricular haemorrhage, to meningitis and seizures. The hand of a master is obvious in every chapter. Extensive use of clinical photographs, flow diagrams and summary tables break up the dense text into readable chunks. The reader also gains considerably from the recent addition of references right up to proof stage (- for example, 387b) - why don't more publishers allow this?

How does this book compare to its more expensive British competitor, Fetal and Neonatal Neurology and Neurosurgery, edited by Levene and Lilford? Levene's book benefits from an obstetric angle, which is a definite strength in these days of prenatal diagnosis. The British book also covers epidemiology, ethics, and a little law with more emphasis on describing investigative techniques. These are all condensed into one chapter by Volpe. The basic science is better covered in the American book which is slightly lighter on discussion of clinical management strategy but with more illustrations. Both failed my index test for several rare conditions, including 'growing skull fracture', although Volpe won hands down on benign neonatal sleep myoclonus. However, this is a trivial game and I would not want to belittle the achievement of either author. Any serious neonatal neurologist will want to own both books. I remember once being puzzled by a review written by David Issacs which began 'I pleaded with the editors to let me review this book...' Now I know how he felt. Go without the animal print tie or silk scarf this spring Professor Volpe may not write a fourth edition.

JANET M RENNIE Consultant in Neonatal Medicine,
King's College Hospital, London

Brain Damage in the Preterm Infant. (pp 209, £45 hardback) Nigel Paneth (Ed) Raoul Rudelli, Elias Kazam, William Monte, Mac Keith Press 1994; ISBN 0521-68300-X.

Since its widespread introduction in the early 1980 s, cerebral ultrasonography has occu pied a central role in the evaluation of brain injury in preterm infants. Technologica advances have brought about increasing clarity and detail in the images produced while other branches of neuroradiology have failed to match ultrasound in terms of accessibility and acceptability for the sick very low birthweight (VLBW) infant. Naturally, such a powerful tool has lead to a plethora of publications relating ultrasound findings to neurological outcome. During the counselling process, parents of a sick preterm infant often seize on the results of a scan, hoping for prognostic certainty. Despite the routine clinical use of cranial ultrasound much work still needs to be done to determine the causation and consequence of damage to the premature brain.

This concise book is based around the Central New Jersey Brain Haemorrhage Study undertaken by the authors during the mid-1980s. It aims to re-examine the nature of brain insults affecting a population of preterm babies undergoing modern neonata intensive care, providing a historical perspective to current neuroanatomical and pathological knowledge. Crucially, it also correlates ultrasound imaging with subsequent post mortem findings of the whole brain
These objectives are achieved in a thoughtful and lucid way with meticulous methodological detail supplied for specialists in histopathology and radiology. Chapters on germinal matrix/intraventricular haemorrhage (GM/IVH) and white matter damage are preceded in each case by explanations of terminology and pathogenesis.

On more than one occasion the authors unearth pertinent literature long since published and discarded by subsequent generations of pathologists. Some persistent misconceptions, such as regarding parenchymal haemorrhage as an extension of intraventricular bleeding, are exorcised in an assertive but scrupulous manner.

The text is superbly illustrated by colour photographs of pathological specimens adjacent to corresponding brain ultrasound and colour Doppler images. However, the educational impact is spoilt by excessive labelling of some images and overlong figure legends.

A splendid chapter dealing with the pathogenesis of GM/IVH presents many individual anatomical and pathological pieces of evidence from over the centuries to substantiate today's concepts. The excellent final section on prognosis gives a refreshingly concise overview of the range and incidence of neurodevelopmental sequelae in VLBW survivors. This is followed by a succint review of published data relating ultrasound abnormalities to outcome.

An important weakness in the original study design is acknowledged - namely, the bias to study haemorrhage by early scanning, now recognised as of lesser importance than white matter damage. I cannot, however, concur with the authors' concluding statement that ultrasound images may act as a proxy for neurological disability, obviating the need for long term follow up studies. Undoubtedly this is a valuable book enabling budding neonatologists, experienced clinicians, and a range of allied professionals, to improve their understanding of brain injury in preterm infants. St Mary's Hospital, Manchester

Fetus and Neonate: Physiology and Clinical Applications Volume 2: Breathing. Edited by Mark A Hanson, John $\mathrm{AD}$ Spencer and Charles $H$ Rodeck (pp 400 f60 hardback) Cambridge University Press, 1994. ISBN 0-521-41765-1.

The authors have set out to fill the gap between large textbooks and review articles, aiming to provide the reader with detailed, up to date information on the physiology of the fetus and neonate, and how this can be adversely affected. Unlike many monographs, they set out to provide a balanced view. They hope that this will be useful to investigators planning to explore the area in greater detail, and to provide those further on in their careers with state of the art information.

In this they have succeeded. They have followed the format adopted in the first volume on the cardiovascular system so that the first half of the book concentrates on the normal developmental physiology of the respiratory system in the fetus and newborn infant. I thought these review statements were excellent and I have already found them a very useful reference source.

The remainder of the book I have found less useful. It is loosely divided into a section 